\title{
Application and Prospect of CFRP
}

\author{
Yixin Chen, Kewei Gao, Yuehui Sun \\ College of Civil Engineering, Tongji University, Shanghai 200092, China \\ hunter2011@foxmail.com
}

Keywords: Application, CFRP.

\begin{abstract}
CFRP is one of the most popular building materials nowadays. People have high hopes for its development and application. While in CFRP possesses the merits of light weight, high strength, fatigue resistance and so on, at the same time, its resistance to damage tolerance is low, the high temperature and humidity resistance of matrix is poor, these defects greatly limited its development. This paper reviewed the characteristics of the CFRP; summarized CFRP's present application situation in bridge engineering with the development order; besides, it puts forward some superficial solutions for its shortcomings and previews the future development of CFRP.
\end{abstract}

\section{The Modern Research View About CFRP}

Carbon Fiber Reinforced plastics (CFRP for short) is one of Fiber Reinforced Plastics (FRP for short), it is a high performance composite material originally wrapped by Carbon Fiber in resin matrix, formed after drawing, extrusion of special mould. During the process, Carbon Fiber reinforces it, while mainly bonds Fiber ${ }^{[1]}$. Common fiber reinforcing plastics also include glass fiber reinforcing plastic (GFRP) and aramid fiber reinforcing plastic (AFRP), the above three kinds of fiber reinforcing plastics have their own advantages. People also conducted a lot of comparative experiments about FRP's characteristics:

Table 1: the performance of three reinforcing fiber plastics compared with that of steel strand

\begin{tabular}{|l|c|c|c|c|}
\hline & CFRP & GFRP & AFRP & steel strand \\
\hline Diameter $(\mathrm{mm})$ & $3.4-14.0$ & $7.5-25.0$ & 7.5 & 15.24 \\
\hline elasticity modulus $(\mathrm{GPa})$ & 131.1 & 51 & 53 & 195 \\
\hline Tensile strength $(\mathrm{MPa})$ & 2400 & 1670 & 1290 & 1860 \\
\hline density(t/) & 1.56 & 2.10 & 1.25 & 7.85 \\
\hline Fatigue resistance & strong & middle & strong & weak \\
\hline Corrosion resistance & strong & weak & strong & weak \\
\hline Damage tolerance & weak & middle & strong & strong \\
\hline
\end{tabular}

Note: damage tolerance - structural resistance to the damage force caused by defects, cracks or other damages

We can notice from table 1 that CFRP has approximate elastic modulus of steel strand, and its tensile strength is higher than the other two kinds of reinforcing fiber plastics. In the aspects of elasticity modulus, fatigue resistance and corrosion resistance, CFRP has greater advantages. Therefore CFRP is very popular in recent years. CFRP can not only replace the prestressed steel strand and ordinary steel bar's functions of enforce prestress, tension resistance in concrete, but also eliminate the problems in the civil engineering field brought about by steel corrosion and fatigue. At the same time, CFRP's small diameter and low density can reduce the weight of bridge, which is basic to improve the span essentially; and CFRP is flexible, reusable, therefore it greatly convenient to construction, bringing possibility of further speed up the bridge construction; its linear elastic intensity is high, and there is no obvious yield point, besides, its seismic performance is greatly improved, which brings hope for mankind to further mitigate earthquake disasters. 


\section{The Present Application of CFRP in Bridge Engineering}

CFRP's reinforcement function on the bridge. When use CFRP to reinforce the bridge, to some extent, its damage tolerance can be complemented by existing structure, and its advantages can be fully played: CFRP's strengthening methods can be used to concrete, brick, steel, wood and other materials; the construction process is convenient, there is no need for large machines; its weight is almost increasing with no break, thus, there is no further damage to the original structure; effective and quick, which means reinforce the bridge one day, the next day the bridge can be opened to traffic, which is very important to the high speed development of economy. Nowadays, the commonly used CFRP reinforcement methods are mainly the following three types presently in accordance with the order of the development: surface paste method, embedding method, prestressed reinforcement method.

(1) Surface paste strengthening method of CFRP. CFRP's surface paste method is the first to be used, this kind of construction method is very simple, and regulations are formulated in all countries ${ }^{[2]}$. The construction process of reinforced concrete structure is mainly: basic level processing (remove the weathering level of the concrete that is to be reinforced, then smooth it) $\rightarrow$ besmear and brush the structural adhesive (leveling required) $\rightarrow$ glue the carbon fiber (avoid bubble residue between CFRP slice and structural adhesive) $\rightarrow$ besmear and brush structure adhesive again $\rightarrow$ coat protection surface $\rightarrow$ inspect and repair.

(2) Embedding reinforcement method of CFRP. The surface pasting method of CFRP's embedding reinforcement method makes the side bond into three sides bond, which greatly improves the bond strength of CFRP and the bearing capacity of the building. In addition, in this method, the CFRP hides in the concrete body, to a certain extent, avoided erosion from environment to the substrate, and also avoided the vehicle collision and man-made destruction. Besides, due to the fact that part of it can adapt to the irregular surface of concrete component, in recent years, it is probable that the CFRP embedding method will replace the paste method ${ }^{[2]}$.

In the construction process of reinforcing concrete component, compared with traditional methods, there is no need of grinding, repairing and leveling the concrete surface layer by using CFRP embedding method. Thus, the use of CFRP embedding method requires no big workload. The processing steps are mainly: slotted $\rightarrow$ infuse glue $\rightarrow$ embedded CFRP tendons $\rightarrow$ fill the structural adhesive $\rightarrow$ coat protective surface $\rightarrow$ inspect and repair.

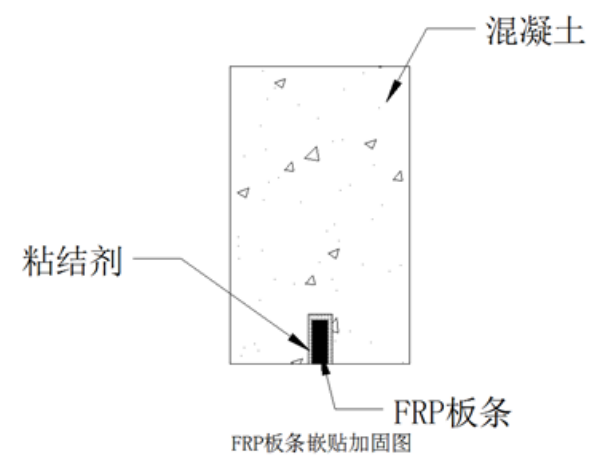

Fig. 1. The embedding consolidation method of CFRP

Although the embedding method improves some defects of the surface paste method, but these two kinds of CFRP reinforcing methods has hysteresis phenomenon, CFRP can only carry the secondary stress. Before reinforcement construction, it is no doubt that the beam should be unloaded first, thus to reduce the deformation degree of steel and concrete, finally to ensure the tensile stress effect on steel be passed to the carbon fiber as much as possible, and both strengths can work coordinately. Besides, these two methods can not offset the stiffness is insufficient problem of bridge structure, thus cannot solve the disadvantages of deforming and crazes. 
(3) Prestressed Reinforcement Method of CFRP. If the bridge is already damaged with crazes, the common strengthening methods of CFRP can't repair the damage, but if certain compressive stress of prestressed CFRP strengthening technology can imposed the structure, it can not only effectively closed fractures, improve the rigidity, but also can effectively play the tensile functions of CFRP ${ }^{[3]}$. Surface paste strengthening method and embedding reinforcement method of CFRP can be both implemented to the prestressed reinforcement.

After using prestressed strength, the reinforcement method of CFRP performs has obvious effect in the aspects of improving flexural bearing capacity of components, increasing the overall stiffness, making fatigue life more longer, and reducing the deflection of components. In 1990, people started the research on prestressed strength of embedding method of CFRP. ${ }^{[1]}$ At that time, the main problem how to develop an anchor head.. Commonly used prestressed construction technologies are (1) arch method; (2) anti-arch method; (3) independent bed stretching method; (4) surround the cloth at the bottom of components; (5) stretching method on the components. All these methods have their own characteristics, have certain practical value, but also not without disadvantages: (1) the prestressed level of arch method and anti-arch method are low , and require the use of large hydraulic lifting equipment, (2)anti-arch method could do certain degree of damage to arch beam; (3) independent bed stretching method needs large traffic tools to support, so the cost is high, it can only be applied to experimental study; (4) the method of surrounding the cloth at the bottom of components would waste CFRP cloth, thus not suitable for the reinforcement construction with large span; (5) the method of stretching method on the components is simple, costs less human labor and suitable for beams with various lengths, therefore it has great practicability ${ }^{[4][5]}$.

Even if by the method of imposing prestressed strength overcomes the defects of common CFRP's strengthening methods - under use the tensile strength of materials, lack of control over bridge deflection, cracks, people still are not satisfied with CFRP's prestressed reinforcement effects. Due to the CFRP deformation's low coefficient, the structure is brittle, besides, the unsuitable anchorage will lead to weak anchoring. These problems still need further study to be solved.

CFRP applied to the Real Bridges. Due to the fact that there are no clear design specifications and enough experience in using CFRPs, there are also a lot of unsolved defects. Apart from the cost problem, there are few examples replacing steel or concrete with CFRP in bridge construction. But people's passion for CFRP application hasn't stopped. There are several successful application cases of the application of CFRP on part of maturity structure's components, such as prestressed reinforcement of bridge beam, cable of cable-stayed bridge and cable of suspension bridge.

(1) CFRP Used for Prestressed Reinforcement. CFRP's low relaxation and high tensile strength not only could reduce the loss of the prestressed relaxation, but also enhance the prestressed effect. Japan is the first one using CFRP for prestressed reinforcement, and in 1988, it built two Shinmia highway bridges one after another: spanning $5.76 \mathrm{~m}$ with $7.0 \mathrm{~m}$ of width. In 1991, Germany applied CFRP stranded wire with post-tensioned prestressed method on the east bridge, and with wedge anchor system bond the wire on the beam. ${ }^{[1]}$

(2) CFRP Applied in the cable of Cable-Stayed Bridge. If people want to continue to increase the span of cable-stayed bridge, when the cable is too long, it will drop down under its weight, and the joint of bottom and girder will close to tangent, thus the bridge can no longer bear vertical load and provide vertical supporting power, finally lost the supporting function of cable acting as vertical elastic girder. So, CFRP replacing steel cable can not only resist corrosion, but also could decrease weight and increase the span of cable-stayed bridge by adopting CFRP. At present, both at home and abroad, CFRP cables established small number of bridges with experimental cable-stayed bridge parts: 
Table 2: CFRP small cable-stayed bridge at home and abroad ${ }^{[6]}$

\begin{tabular}{|c|c|c|c|c|}
\hline Bridge name & Country or area & Type & Span/length/m & Finish time \\
\hline Store Bridge & Switzerland & Road bridge & $61 / 124$ & 1996 \\
\hline Tskuba city footbridge & Japan & Foot bridge & $11 / 20$ & 1996 \\
\hline Herning & Denmark & Foot bridge & $40 / 80$ & 1999 \\
\hline 1-5/Gilman & America & Road bridge & $95.3 / 137.3$ & 2002 \\
\hline $\begin{array}{l}\text { Laroin city cable-stayed } \\
\text { bridge }\end{array}$ & France & Foot bridge & $110 / 110$ & 2003 \\
\hline $\begin{array}{l}\text { Jiangsu University } \\
\text { experimental bridge }\end{array}$ & China & Foot bridge & $30 / 50.1$ & 2005 \\
\hline
\end{tabular}

(3) CFRP used as Suspension Bridge Cable. For the bridges spanning over 5000 meters, the ratio of the collection degree of the constant and live load and the cable's weight will reach 1.0 or so, thus, the structure can only bear the cable's gravity ${ }^{[7]}$. So to achieve a breakthrough in span, the only way is to lose weight, at the same time, the main structure tension and anchorage force will be reduced correspondingly. The low density of CFRP is an advantage will again bring hope again to the study here. From the the current situation of the development of suspension bridge, the small span suspension bridge cable has relatively little weight, there is such problems as low bearing efficiency and construction difficulty. Therefore, using CFRP cables cannot full play to the superiority of CFRP, so CFRP is more appropriate for long-span suspension bridge cable system. In Kurushima suspension bridge (1030 m span), Japan for the first time applied CFRP as the main cable material, which provides a reference for future large suspension bridge design.

(4) CFRP Used for Seismic Design. CFRP itself is fatigue resistance with high ductility, while in face of dynamic load it has stronger resistance towards natural disasters. At present, in bridge structure seismic applications, it is more used to paste around the bridge pier top and pier foot, thus to replace the stirrups' constraints to pier. While increasing resistance power, CFRP wrapping on the surface of reinforced concrete parts, component's rigidity experienced little change, thus will not lead to the bear of the more components seismic load, but the increase of the shear strength, the falling of concrete and its longitudinal reinforcement buckling have been limited, besides, it avoids the damage and sliding of longitudinal reinforcement of the lap joint ${ }^{[8]}$.

\section{The Prediction and Prospects of the Application of CFRP - Apply CFRP to Bridge Construction}

Bridge construction is far more complicate than building construction, for the stress resistance characteristics are different in different construction phases and by using different construction methods. The structure shape, material properties, boundary conditions and loads and structure deformation during the construction process consistently make the internal force distribution renew itself, and bridge structure design and the steel type should both be based on the normal situation and take the the impact of the construction load into consideration. Especially the jacking construction method, in the construction process, each section will experience bending moment, and the reinforcement should take the construction load into consideration and use composite reinforcement in the bridge beam's bending area, which lead to the waste of materials. If CFRP materials were put into use in beam reinforcement, the beam reinforcement only based on the normal situation, and during the construction, we just paste some temporary CFRP sheets on the beam section. To cope with the temporary construction stress, after the construction finished, take down the CFRP sheets from the beam, through a simple filter processing, this sheet can be applied to other jacking construction engineering. This is equivalent to the pusher to the situation that, when the top come to a dangerous position, firstly support the beams to a certain degree, after the pushing arrived in normal position, withdraw the support, yet, the structure still functions well. Although the cost of CFRP is high, due to the fact it is reusable, sustainable, after many times of use, the cost may not limit its development. 


\section{References}

[1] X.D. Hao. Research on the Stress Tolerance Properties of CFRP Arc Bridge. Master degree theses of chang 'an University, 2013,4,26.

[2] J. Sun, S.H. Sun, R.G. Hu. The Application and Prospect of Carbon Fiber Composites used in Bridge Engineering. Highway traffic technology. 2004, 2-1.

[3] M. Su, Prestressed Reinforcement of FRP Embedding Method on Concrete Beams. Transportation world built (mechanical), 2012 (11).

[4] Y.W. Su, Study on the Flexural Performance of Damaged Reinforced Concrete Beams with Prestressed CFRP. Construction technology. 2014, 43-4.

[5] S.P. Shang, H. Peng. Prestressed CFRP Materials Research on the Bending Capacity of Reinforced Concrete Parts. Journal of Building Structures, 2003,21-5.

[6] Q. Xie, Z.D. Liu, J.T. Yu. Several issues about prestressed FRP reinforced concrete structure. Industrial buildings.

[7] C.S. Zhang, X. Zhao, Y.H. Ding, The overview of Embedded Prestressed Fiber Reinforced Concrete Beams. Glass steel/composite materials, 2014.10.

[8] M.K. Xu. The Development of Carbon Fiber Composite Cables. Fiber composites, 2010,9.

[9] H.J. Wu, P. Lu, Z. Zhou, The Application and Prospect of CFRP in Future Bridges. Journal of Chongqing Transport Institute. 2004-2.

[10] Z.S. Wu, The Present Situation and Future Development of FRP Composite Materials in the Reinforcement of Basic Engineering Design. China's First Fiber Reinforced Plastics (FRP) Concrete Structure Academic Exchange Conference Proceedings, Beijing, 2000. 